\title{
Effect of Side Groove on Shear Lips Formation of Aluminium Alloy 6061 using Finite Element Analysis
}

\author{
Mohd Azmeer Asry ${ }^{1}$, Mohd Azhar Harimon ${ }^{1 *}$ \\ ${ }^{1}$ Faculty of Mechanical and Manufacturing Engineering, \\ Universiti Tun Hussein Onn Malaysia, Parit Raja, Batu Pahat, Johor, 86400, MALAYSIA \\ *Corresponding Author
}

DOI: https://doi.org/10.30880/jamea.2021.02.01.005

Received 06 June 2021; Accepted 18 July 2021; Available online 02 August 2021

\begin{abstract}
Aluminium alloys are commonly utilised to reduce the weight of vehicles as structural components due to their good mechanical properties, lightweight characteristics, ease of fabrication, and high specific strength. During an accident, aluminium alloys are subjected to high velocity and varying loads. As a result, it is crucial to understand the impact properties of aluminium alloys. The side groove influence on the shear lip development of the aluminium alloy Al6061 was investigated in this study. The Charpy impact test under different side groove depth ratio was conducted through simulation using Abaqus. It was found that the shear lips ratio decreased when the side groove depth ratio increased. The energy absorption and force required to fracture the specimen decreased when the side groove depth ratio increased. As a result of the lower shear lips ratio, less absorb energy, and less force of impact, increasing the side groove depth ratio will tend to lower Al6061 ductility.
\end{abstract}

Keywords: Shear lips ratio, FEM simulation , side groove depths, Al6061, Charpy impact test

\section{Introduction}

Aluminium alloy can be classified as non-ferrous metal, which is the composition of other materials with Aluminium as the dominant material. Aluminium alloy is widely used in engineering, such as building structures and other engineering designs, because it is easy to combine with other alloying metals to obtain desired characteristics and can be made in a variety of ways [1]. Aluminium alloy 6061 or Al6061 are widely used in the construction industry and also used commonly in automotive components such as body components, power-train casting, and suspension parts [2]. All materials that undergo the process of fracture have their fracture behavior. Fracture behavior is frequently linked to micromechanic fractures and the fracture process in terms of stabilization. The material's fracture behavior is classified as ductile or brittle [3]. Because of its properties, pure Aluminium frequently fractures in a ductile manner [4].

A side groove is one type of groove that can be defined as a deep line cut on the surface of a specimen. According to Hess et al. [5], side groove can stimulate plane strain fracture in a thin section of a specimen that usually has ductile behavior. Thus, the use of a side groove is important, especially to the small specimen, and it can increase the percentage of the notch or crack front when the experiment was conducted [6]. The shear lip is an important characteristic in fracture mechanics, especially to show the ductile fracture on the specimen. Before the fracturing hits the surface, the order from the transverse to around $45^{\circ}$ inclined can unexpectedly be shifted where it is most common. This surface of fracture is called a slant fracture or shear lip where it forms the cup and cone shape for essential tensile fracture of ductile metal. Furthermore, this shear lip formation at the surface of a material can be in single or double where the plane stress state exists [7]. The small area of the shear lip with less than 10 percent is the same as the brittle fracture and rapid crack growth, based on previous study [8].

The Charpy impact test also can be done using finite element method (FEM) simulation through any related software such as Abaqus. The model of this test can be divided into three major parts which is the striker, the anvils and the 
specimen [9]. Besides that, the rigid bodies or elastic bodies were used for the model of striker and anvils while for the specimen considered as deformable. The type of mesh can be divided into finer mesh at the notch region and the coarse mesh at the remaining part of the specimen [9]. Apart from that, Abaqus software may be used to estimate shear lip development during a fracture, where certain studies have shown that shear damage is greatest along a slant plane, resulting in shear lip formation. The fracture energy, as well as the maximum Von misses stress, maximum displacement, and absorbed energy by impact, can be calculated using Abaqus software [10].

Many studies have reported the effect of side grooves on fracture behavior, crack initiation, stress, and strain, as well as deformation conditions in side grooved samples [11]-[13]. However, published studies in this field devoted little attention to the influence of varying depths of side-grooves. As a result, the side-groove specimen test technique is a major and suitable test method, particularly under high loading rate circumstances. As a result, it is critical to investigate the impacts of aluminium alloy side grooves at various depths further. In this study, the fracture behavior of aluminium alloy 6061 will be investigated through FEM of the Charpy impact test by using the Abaqus software.

\section{Materials and Methods}

\subsection{Size and Material of Specimens}

For this study, the specimen model was made of aluminium alloy (A16061), whereas the striker model was made of stainless steel. Stainless steel was chosen under the ASTM E23 requirement [14]. Table 1 shows the material properties of Al6061 and stainless steel. The Charpy impact test was simulated using the Abaqus 6.14 software where the striker model was set with the initial velocity of $2500 \mathrm{~mm} / \mathrm{s}$. Fig. 1 shows the model that had been constructed for the Charpy impact test. The geometry of the specimen for this test was set at 10, 1.66 and $50 \mathrm{~mm}$ in width, length of the notch, and total length of the specimen model, respectively. Next, for the striker model, the radius was set at $0.8 \mathrm{~mm}$ at the end of the model and $20 \mathrm{~mm}$ at the length, while it has a little gap of $1.5 \mathrm{~mm}$. The side groove was created in the middle of the model, where it was located above the notch. The shape of the side groove was modeled as a rectangular shape on the specimen model. Besides that, a double side groove was presented at the front and the back of the model. Different side groove depth ratios set at $0,0.1,0.2$ and 0.25 for investigating the shear lip formation, energy absorption and force required towards different side groove depth ratios.

Table 1 - The properties of material of Al6061 and stainless steel

\begin{tabular}{lccc}
\hline Parameter & Specimen Model & Striker Model & Unit or Dimension \\
\hline Young's Modulus & 70.0 & 193 & $\mathrm{GPa}$ \\
Poisson's Ratio, $v$ & 0.33 & 0.31 & - \\
Density, $\rho$ & 2600 & 7750 & $\mathrm{~kg} / \mathrm{m}^{3}$ \\
\hline
\end{tabular}

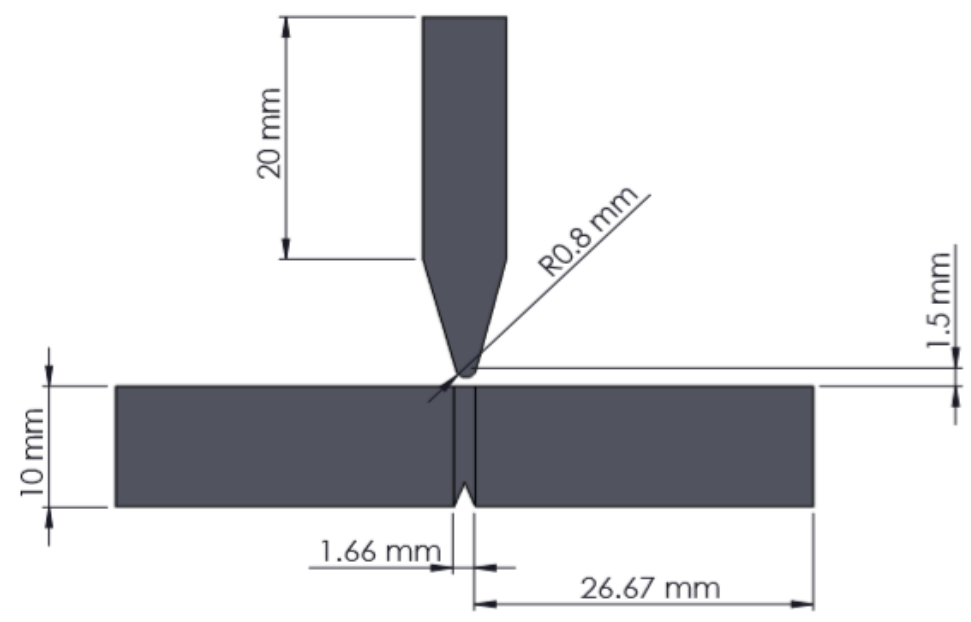

Fig. 1 - The assembly striker part with the specimen of the Charpy impact test

\subsection{Finite Element Modeling}

The process flow must be properly understood when conducting a simulation experiment. The process flow that was used in this study is represented in Fig. 2. All steps must be carried out with caution. Otherwise, it will have an impact on the final results. Because of its capability to forecast failures in many engineering materials, the Johnson-Cook Model was used for this study to simulate fracture for aluminium alloy 6061 [15]. According to the parameter for Al6061 
acquired from the other research experiment, the Johnson-Cook material model was used to the specimen model, as stated in Tables 2 and 3 [16].

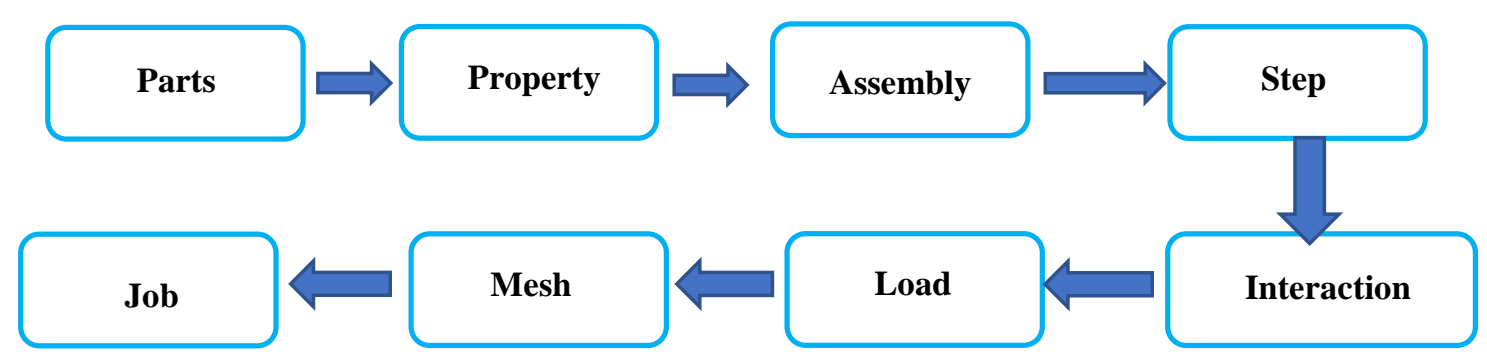

Fig. 2 - The process flow of simulation using Abaqus

Table 2 - The Johnson-Cook material model for Al6061 [16]

\begin{tabular}{lcc}
\hline Parameter & Specimen Model & Unit or Dimension \\
\hline A & 324 & $\mathrm{MPa}$ \\
$\mathrm{B}$ & 114 & $\mathrm{MPa}$ \\
$\mathrm{C}$ & 0.002 & - \\
$\mathrm{n}$ & 0.42 & - \\
$\mathrm{m}$ & 1.34 & - \\
\hline
\end{tabular}

Table 3 - The Johnson-Cook damage model for Al6061 [16]

\begin{tabular}{cc}
\hline Parameter & Specimen Model \\
\hline d1 & -0.77 \\
d2 & 1.45 \\
d3 & 0.47 \\
d4 & 0 \\
d5 & 1.6 \\
\hline
\end{tabular}

The surface-to-surface contact interaction that has been set between the specimen and striker model is depicted in Fig. 3. It has two major surfaces for obtaining data for absorbing energy and force, as well as for analyzing fracture behavior. The Charpy impact test meshing is shown in Figure 4. Meshing was significant since it represented an element, and the time to solve was influenced by the meshing criterion. In one study, a hexagonal shape was created using the sweep technique and applied to the middle of a specimen model with a notch, while others used a structured technique to create a hexagonal mesh shape.

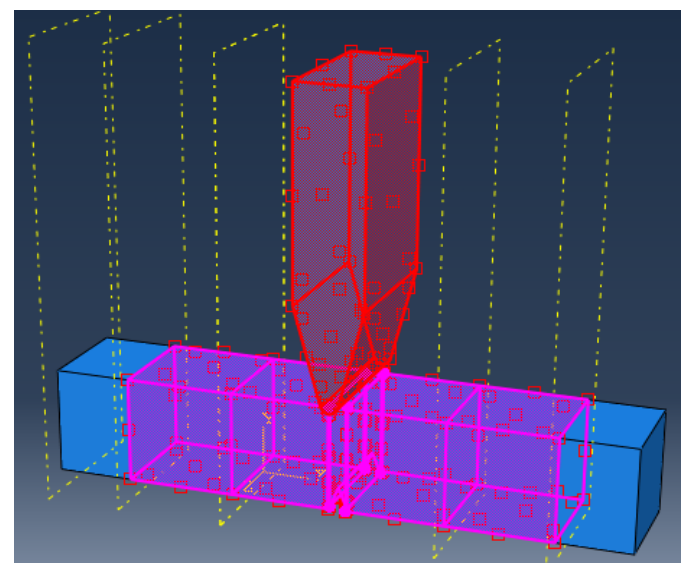

Fig. 3 - The interaction between specimen and striker model

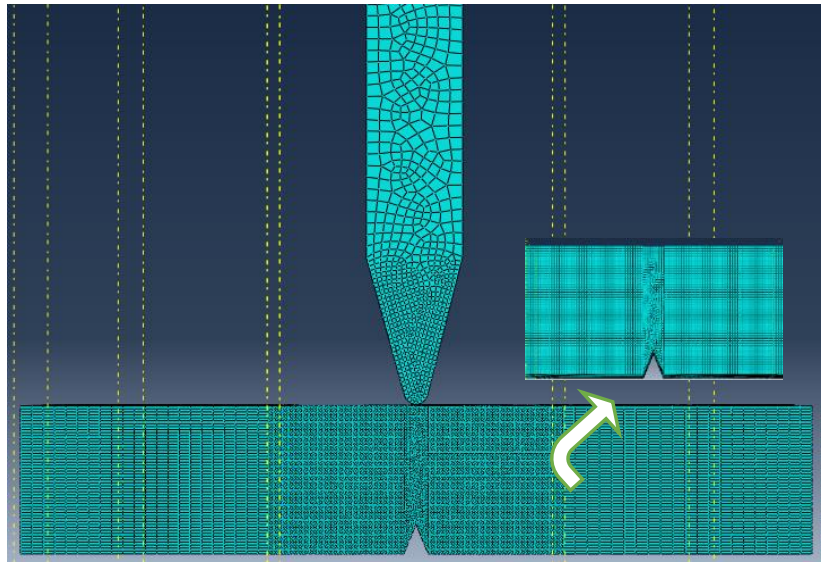

Fig. 4 - The meshing of Charpy impact test 


\section{Results and Discussion}

According to some study, the plastic strain contours were required to calculate and assess the shear lip ratio using simulation techniques [17]. Plastic strain contours, abbreviated as PEEQ in Abaqus, were plotted on the crack face for each example. Some experts suggest that, if the shear lips ratio is less than $10 \%$, the material will exhibit brittle behavior and crack growth will be more rapid [18]. Aside from that, Fig. 5 depicts the fracture surface with shear lips based on the side groove depth ratio. The shear lips ratio was determined using the table published by ASTM E23, and the value of the shear lips ratio in this investigation was represented by the graph in Figure 6. Shear lip development is a facial crack with a green tint on both sides. The shear lips ratio for all side groove depth ratios was found to be greater than $10 \%$. This shows that all the specimens were ductile fractured rather than brittle fractured. The shear lips ratio decreases when the side groove depth ratio increases, as seen in Fig. 6. As the depth increases, the shear lips ratio decreases, and the ductile fracture becomes brittle. This is because the smaller the shear lips ratio, the tendency to reach brittle fracture was high.

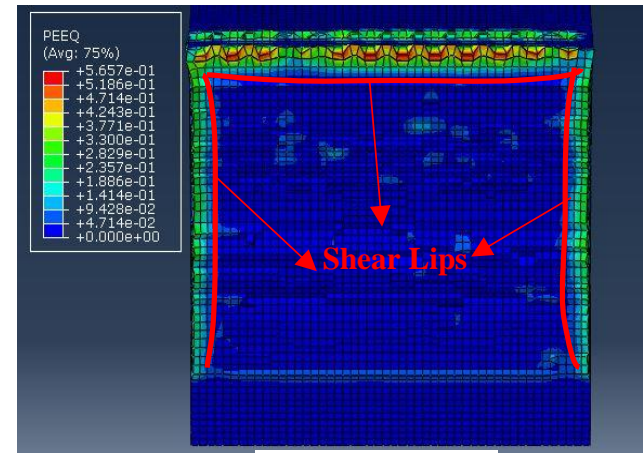

(a)

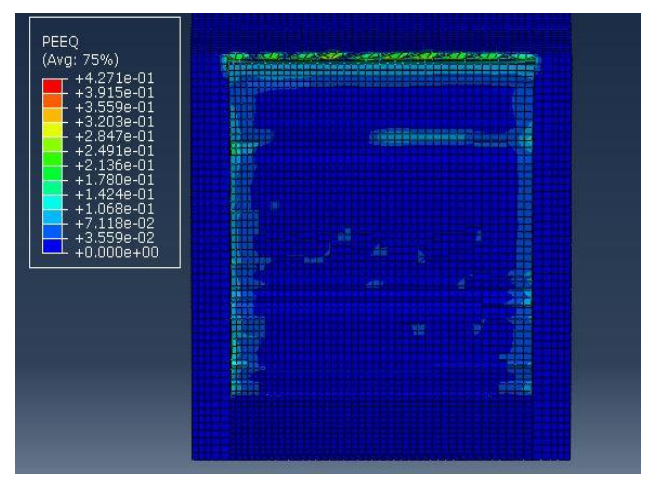

(c)

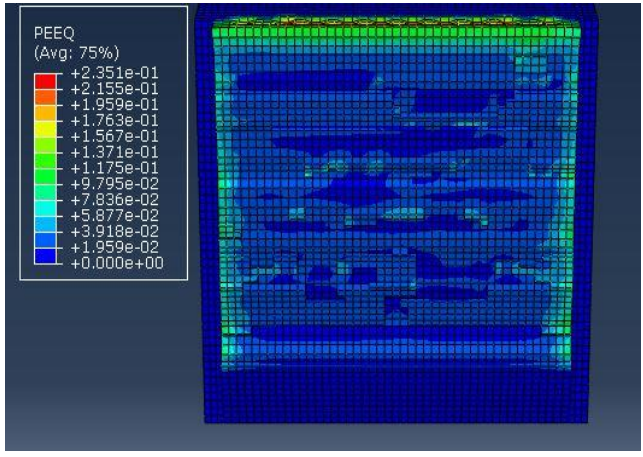

(b)

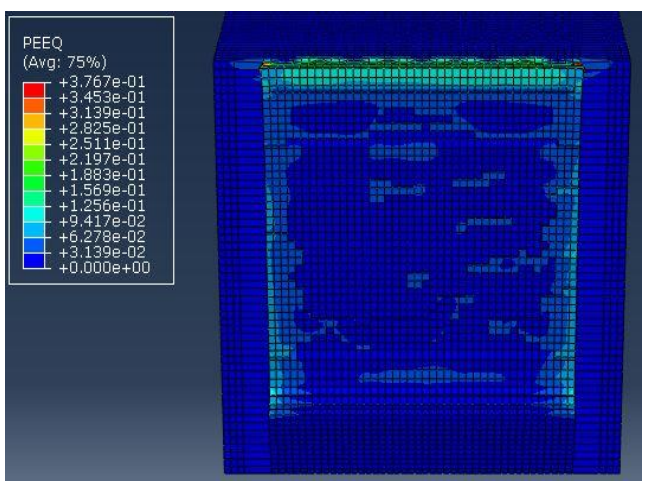

(d)

Fig. 5 - The fracture surface contained shear lip formation on various side groove depth ratios, (a) 0.0 ; (b) 0.1 ; (c) $0.2 ;$ (d) 0.25

Shear lips ratio vs Side groovedepth ratio

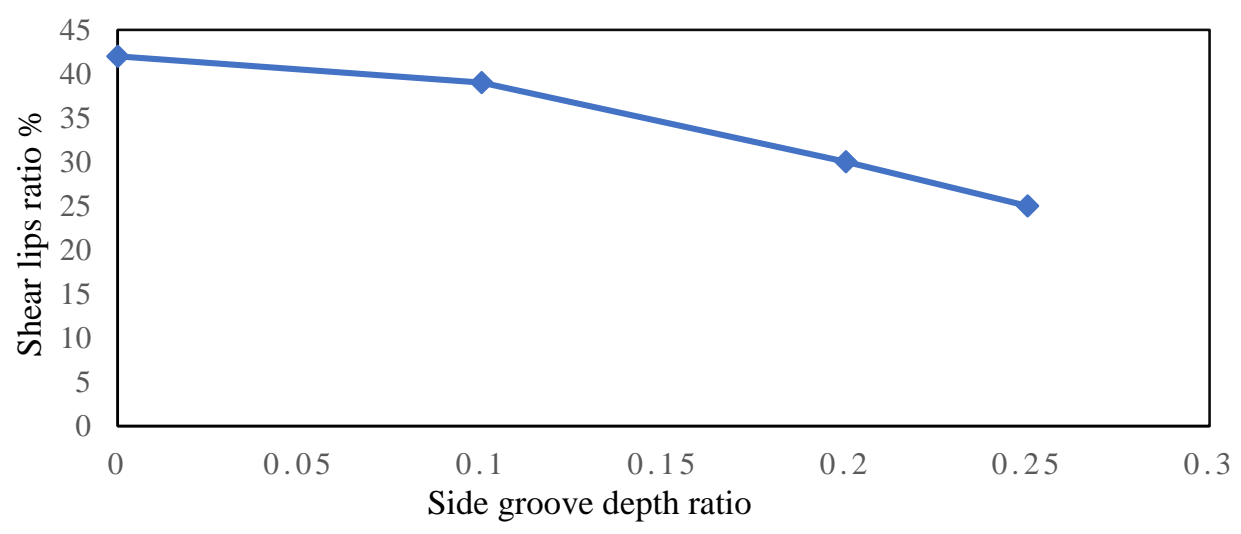

Fig. 6 - The relationship of shear lips ratio with various side groove depth ratios 
Table 4 illustrates the results of the study's shear lips ratio, maximum absorption energy, maximum displacement, and maximum force calculations for various side groove depth ratios. The data was acquired using Abaqus features via ODB history output for maximal absorption energy. When doing the Charpy impact test, absorption energy was a crucial factor. The data have been collected after completing the time increment until $0.003 \mathrm{~s}$. The maximum absorption energy has reduced as the side groove depth ratio has increased, according to the graph in Fig. 7 . The pattern of the data is consistent with previous research findings [10], which demonstrate that as absorption energy decreases, the specimen will exhibit brittle fracture behavior. For each scenario, Fig. 8 shows the total absorption energy corresponding to the time increment. When compared to certain experimental study, the finding indicates that the deeper side groove will exhibit brittle behavior [19]. When the Charpy impact test was conducted, increasing the side groove depths resulted in a low absorption energy result. As a result, it can also be concluded that the reduced absorption energy during fracture will results in fast crack propagation or brittle fracture.

Table 4 - The fracture properties of Al6061 at different side groove depths

\begin{tabular}{ccccc}
\hline $\begin{array}{c}\text { Side Groove } \\
\text { Depths Ratio }\end{array}$ & $\begin{array}{c}\text { Shear Lips } \\
\text { ratio (\%) }\end{array}$ & $\begin{array}{c}\text { Maximum Absorb } \\
\text { Energy (J) }\end{array}$ & $\begin{array}{c}\text { Maximum } \\
\text { Displacement } \\
(\mathbf{m m})\end{array}$ & $\begin{array}{c}\text { Maximum } \\
\text { Force (N) }\end{array}$ \\
\hline 0.0 & 42 & 1987.02 & 5.99548 & 5736.18 \\
0.1 & 39 & 1115.45 & 6.42021 & 5231.43 \\
0.2 & 30 & 1020.5 & 6.67169 & 4975.21 \\
0.25 & 25 & 824.587 & 6.91315 & 4110.76 \\
\hline
\end{tabular}

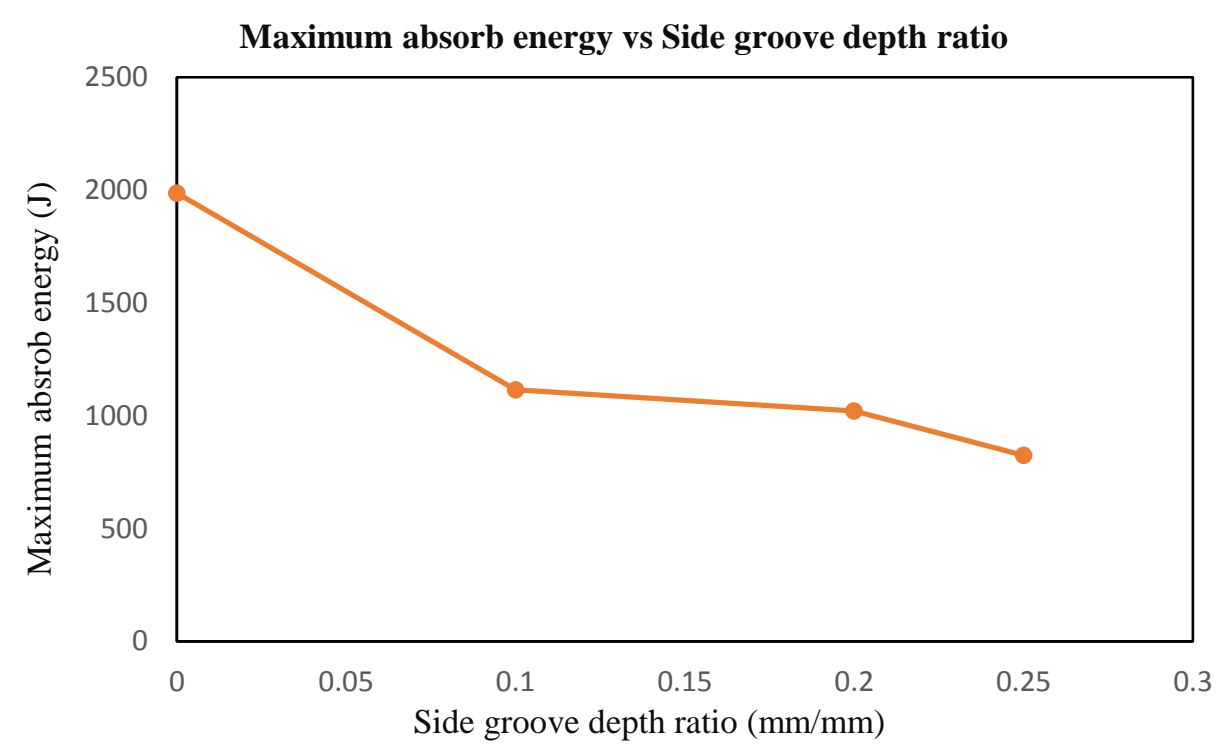

Fig. 7 - Graph of maximum absorb energy versus side groove depths ratio

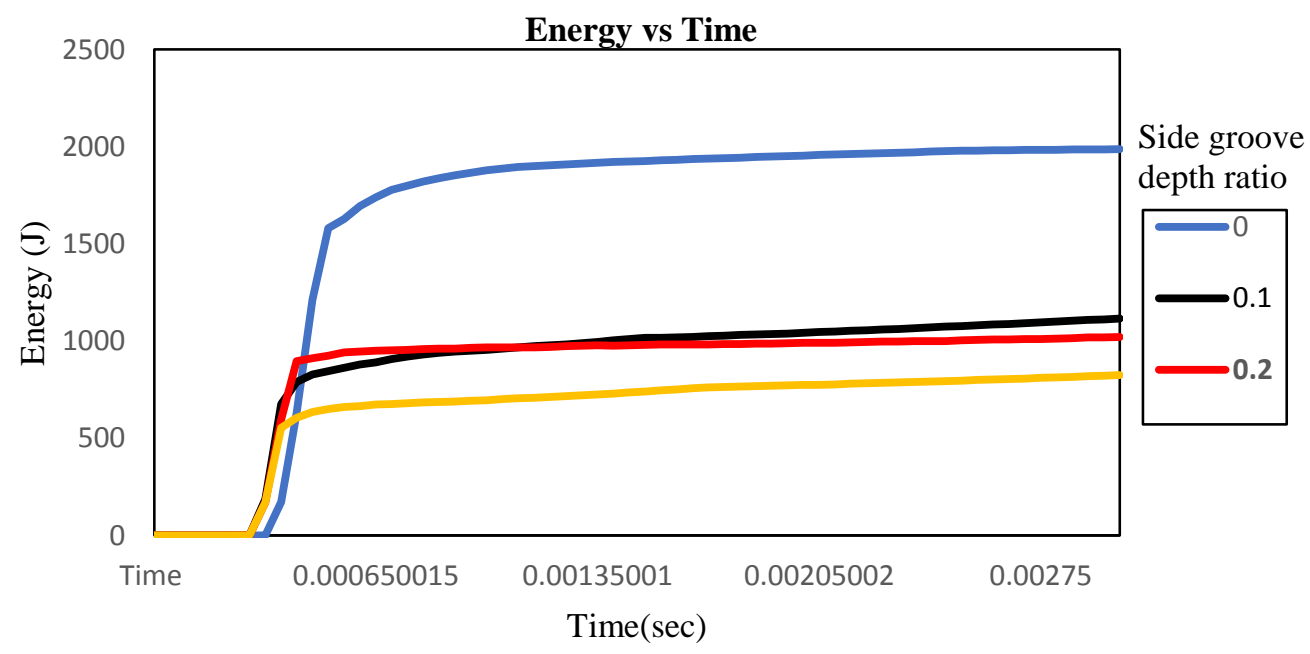

Fig. 8 - The absorb energy versus time plot of Al6061 for various side groove depth ratios 
The data for the specimen model's fracture displacement for various side groove depth ratios is then shown in Fig. 9. After a completion time of 0.003 seconds, the result emphasized on how much damage the crack or fracture did to the specimen model. Aside from that, the first half of the graph in Fig. 9 can be viewed as a parallel line to the time axis, and it changes the displacement axis multiple times to achieve the maximum value. The incubation time is represented by this parallel line. This means that the Al6061 does not fracture during this time, but after the incubation period is over, it begins to crack [10]. The displacement versus time curves move toward greater displacement at higher side groove depth ratios. It was also discovered that raising the side groove depth ratio increases the likelihood of early Al6061 failure when the maximum displacement is high [10].

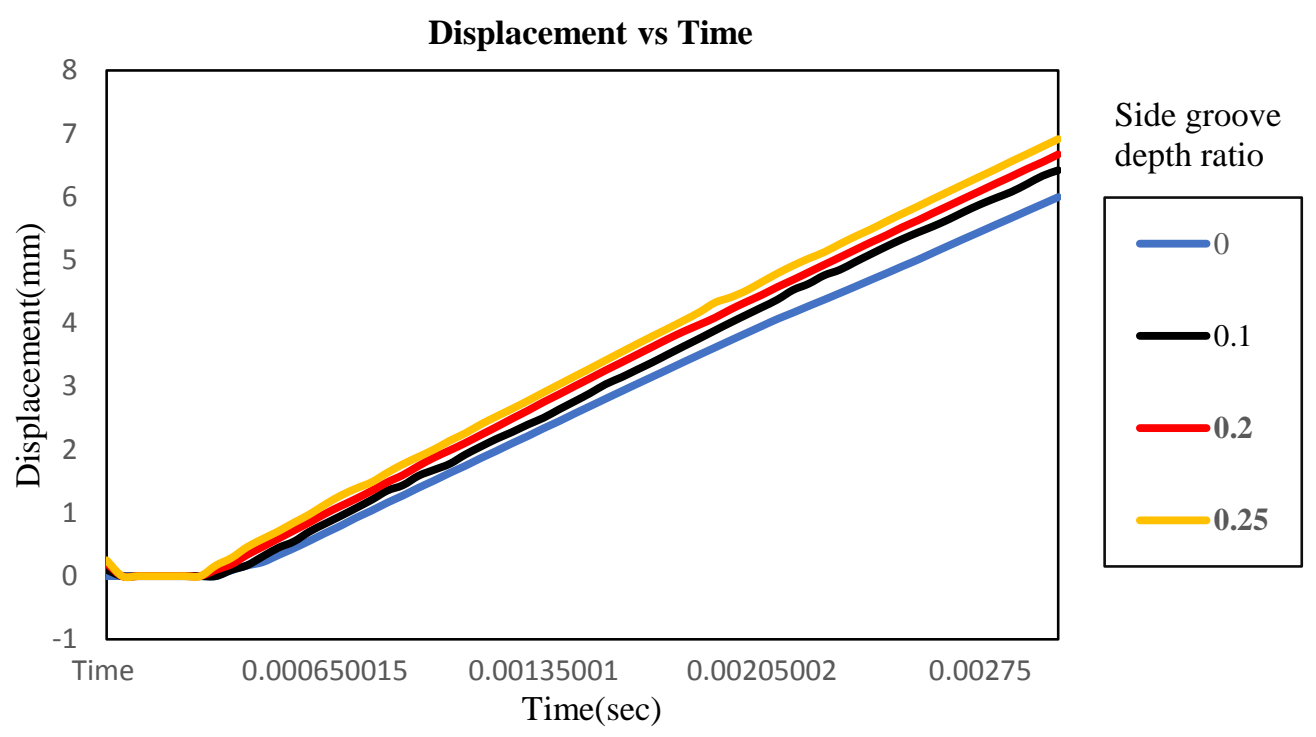

Fig. 9 - The graph of displacement against time for various side groove depth ratios

Furthermore, force is critical when conducting any experiment testing, particularly when addressing how much force was required to establish the fracture when a side groove was present. The interaction between the striker model and the specimen model yielded the data for this force. The graph of all data shows the same pattern, but the most essential thing is to know the maximum force required required to completely fracture the specimen model into two parts. The graph in Fig. 10 demonstrates that as the specimen model is shattered, the force diminishes once it achieves a higher force at a given displacement. The maximum force in Fig. 10 can be considered as the nominal start of fracture initiation, according to Fang et al. [20]. The graph's trend agrees well with Fang et al. [20], showing that force-displacement behavior stops once shear lips form. Aside from that, Fig. 10 also depicts the area beneath the graph, which reflects the overall effort done during the impaction. When the side groove depth ratio is increased, the area beneath the graph shrinks. It's reasonable to determine that, by increasing the side groove depth ratio, the specimen model required less force and energy to fracture. 


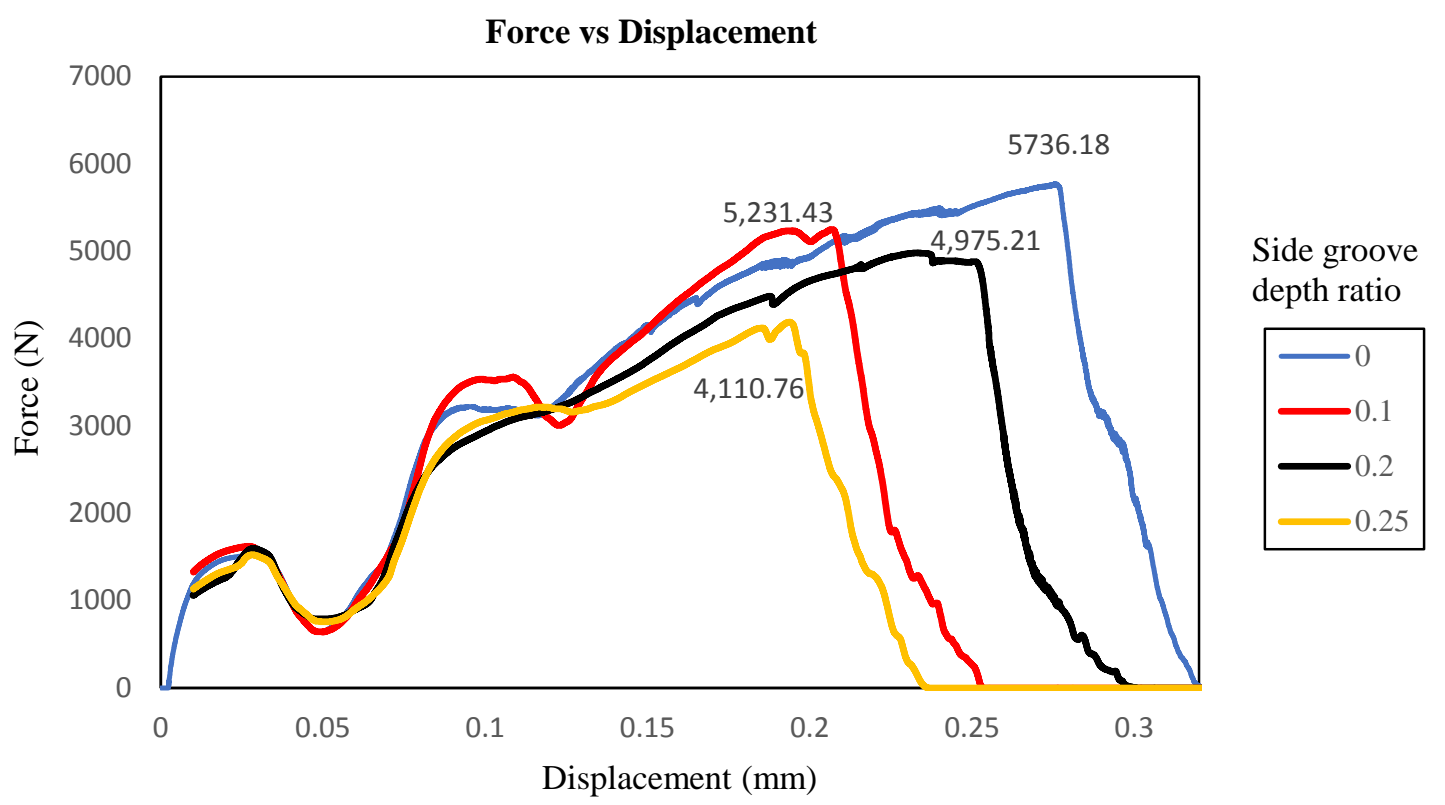

Fig. 10 - The graph of force against displacement for various side groove depth ratios

\section{Conclusion}

A Charpy impact test was carried out under varied side groove depths using the finite element method (FEM) software for Al6061 alloy applications. Plastic strain contours revealed a decrease in shear lips as side groove depth increased. It can be seen that when the side groove depth ratio increases, the shear lips ratio drops, but does not reach $10 \%$ instead of merely 25\%. This can be assumed as the Al6061 still on ductile fracture behaviour and undergo plastic deformation before it is fully fractured. When the deeper side groove is used on the specimen model, less absorb energy is required, since less absorb energy contributes to brittle fracture. Furthermore, by increasing the side groove depth ratio, the outcome result of the force required to fracture the specimen was decreased. Less force is needed to break the specimen model until fracture when a higher side groove depth ratio applies for it.

\section{Acknowledgement}

This research was supported by Ministry of Higher Education (MOHE) through Fundamental Research Grant Scheme for Research Acculturation of Early Career Researchers (FRGS-RACER) (RACER/1/2019/TK03/UTHM//2) or Vot No. K152. The authors would also like to thank the Research Management Center (RMC) and Faculty of Mechanical and Manufacturing Engineering (FKMP), Universiti Tun Hussein Onn Malaysia for its support.

\section{References}

[1] M. P. K. Suragimath and G. K. Purohit, "A study on mechanical properties of aluminium alloy (LM6) reinforced with $\mathrm{SiC}$ and fly ash," IOSR J. Mech. Civ. Eng., vol. 8, no. 5, pp. 13-18, 2013

[2] J. C. Benedyk, "Aluminum alloys for lightweight automotive structures," in Materials, design and manufacturing for lightweight vehicles, Elsevier, 2010, pp. 79-113

[3] X.-K. Zhu and J. A. Joyce, "Review of fracture toughness (G, K, J, CTOD, CTOA) testing and standardization," Eng. Fract. Mech., vol. 85, pp. 1-46, 2012

[4] S. Thomesen, O. S. Hopperstad, O. R. Myhr, and T. Børvik, "Influence of stress state on plastic flow and ductile fracture of three 6000-series aluminium alloys," Mater. Sci. Eng. A, vol. 783, p. 139295, 2020

[5] J. P. Hess, A. F. Grandt Jr, and A. Dumanis, "Effect of side-grooves on fatigue crack retardation," Fatigue $\backslash \&$ Fract. Eng. Mater. \& Struct., vol. 6, no. 2, pp. 189-199, 1983

[6] T. A. Siewert and A. K. Schmieder, "Pendulum impact machines: procedures and specimens for verification," 1995

[7] J. Lu, V. Ventzke, N. Huber, and N. Kashaev, "Material Influence on Crenellation Effectiveness in Damage Tolerant Design,” Procedia Struct. Integr., vol. 5, pp. 263-270, 2017

[8] N. A. Latif, Z. Sajuri, J. Syarif, and Y. Miyashita, "Effect of loading rate on fracture behaviour of Mg-Al-Zn alloys," J. Teknol., vol. 78, no. 6-9, 2016 
[9] Y. Cao, Y. Zhen, M. Song, H. Yi, F. Li, and X. Li, "Determination of Johnson--Cook parameters and evaluation of Charpy impact test performance for X80 pipeline steel," Int. J. Mech. Sci., vol. 179, p. 105627, 2020

[10] D. Madhusudhan, S. Chand, S. Ganesh, and U. Saibhargavi, "Modeling and simulation of Charpy impact test of maraging steel 300 using Abaqus," in IOP Conference Series: Materials Science and Engineering, 2018, vol. 330, no. 1, p. 12013

[11] X. Q. Li, C. X. Wu, J. F. Mao, S. Y. Bao, and Z. L. Gao, "Effect of Various Side Grooves on 3D Crack-Front JIntegral for CT Specimens," in Applied Mechanics and Materials, 2017, vol. 853, pp. 46-50

[12] J. C. Sobotka and R. H. Dodds Jr, "Side-groove effects in three-dimensional small-scale yielding: A load and thickness-scaling model," Eng. Fract. Mech., vol. 102, pp. 218-234, 2013

[13] Y. Huang and W. Zhou, "Stress intensity factor for clamped SENT specimen containing non-straight crack front and side grooves," Theor. Appl. Fract. Mech., vol. 93, pp. 116-127, 2018

[14] C. N. McCowan, T. A. Siewert, and D. P. Vigliotti, Charpy verification program: reports covering 1989-2002. US Department of Commerce, National Institute of Standards and Technology, 2003

[15] A. Banerjee, S. Dhar, S. Acharyya, D. Datta, and N. Nayak, "Determination of Johnson cook material and failure model constants and numerical modelling of Charpy impact test of armour steel," Mater. Sci. Eng. A, vol. 640, pp. 200-209, 2015

[16] S. Pervaiz, S. Kannan, K. Ram, and W. A. Samad, "Numerical modeling of Charpy impact test to determine the fracture characteristics of aluminium alloy 6061," in Fracture, Fatigue, Failure and Damage Evolution, Volume 6, Springer, 2019, pp. 85-88

[17] B. K. Gallant and T. S. Koko, "Shear Lip/Plastic Zone Finite Element Model Development," 2002

[18] N. A. Latif, A. Auspan, M. S. Mustapa, N. F. M. Joharudin, and N. F. Nasir, "Effect of Loading Rates and Single Edge Notch Bending (SENB) Specimen Thicknesses on Shear Lips Formation for Al6061 Alloy," Malaysian J. Microsc., vol. 15, no. 1, 2019

[19] M. H. Kadhim, N. A. Latif, M. A. Harimon, A. A. Chamran, and D. R. Abbas, "Effects of side-groove and loading rate on the fracture properties of aluminium alloy AL-6061," Materwiss. Werksttech., vol. 51, no. 6, pp. 758765,2020

[20] J. Fang, J. Zhang, and L. Wang, "Evaluation of cracking behavior and critical CTOA values of pipeline steel from DWTT specimens," Eng. Fract. Mech., vol. 124, pp. 18-29, 2014 